\title{
Anti-diabetic and antioxidant effects of virgin coconut oil in alloxan induced diabetic male Sprague Dawley rats
}

\author{
Bolanle Iranloye $^{1^{*}}$, Gabriel Oludare $^{1}$, Makinde Olubiyi ${ }^{1,2}$ \\ ${ }^{1}$ Department of Physiology, College of Medicine, University of Lagos, Lagos, Nigeria; \\ *Corresponding Author: bolasunkanmi45@yahoo.com \\ ${ }^{2}$ Department of Physiology, Kogi State University, Ayangba, Nigeria
}

Received 25 September 2013; revised 20 October 2013; accepted 28 October 2013

Copyright (C) 2013 Bolanle Iranloye et al. This is an open access article distributed under the Creative Commons Attribution License, which permits unrestricted use, distribution, and reproduction in any medium, provided the original work is properly cited.

\section{ABSTRACT}

Oxidative stress has been discovered to be involved in the progression of diabetes mellitus. The antioxidant properties of virgin coconut oil (VCO) among other functions might have a beneficial effect in ameliorating the disease. This study was aimed to determine the glycemic and antioxidant effects of VCO in alloxan induced diabetic rats. 24 male Sprague-Dawley rats were divided into 4 groups as follows: control (C), diabetes untreated (DUT), diabetes treated with 7.5 $\mathrm{ml} / \mathrm{kg} \mathrm{VCO}\left(\mathrm{DT}_{7.5}\right)$ and diabetes treated with 10 $\mathrm{ml} / \mathrm{kg}$ VCO (DT 10 ). Alloxan (100 $\mathrm{mg} / \mathrm{kg}$ b.w I.P) was used to induce diabetes and VCO was administered orally once daily for 4 weeks. Fasting blood glucose level was measured on Day 0 (72 hours post alloxan injection) and after 4 weeks. Glucose tolerance test was conducted on the 4th week as well as the determination of serum insulin and liver antioxidant parameters using standard biochemical methods. Values are means \pm S.E.M., compared by ANOVA and Tukey's post hoc test. The results show that VCO significantly reduced the fasting blood glucose level in $\mathrm{DT}_{7.5}$ rats $(132.4 \pm 6.911)$ and $\mathrm{DT}_{10}$ rats $(131.6 \pm 12.2)$ are compared with DUT rats $(320.4 \pm 22.99)$ and improved the oral glucose tolerance. Serum insulin was increased in $\mathrm{DT}_{10}$ rats. GSH activities significantly increased $p<0.05$ in $\mathrm{DT}_{10}$ rats $(0.39$ $\pm 0.022)$ when compared to DUT rats $(0.032 \pm$ $0.004)$. CAT activities also significantly increased $p<0.05$ in $\mathrm{DT}_{7.5}(17.63 \pm 0.61)$ and $\mathrm{DT}_{10}$ rats (30.88 \pm 0.97$)$ when compared to DUT rats $(10.98$ $\pm 0.6)$. SOD activities significantly increased $p<$
0.05 in $\mathrm{DT}_{7.5}(2.634 \pm 0.04)$ and $\mathrm{DT}_{10}$ rats $(2.258 \pm$ $0.32)$ when compared to DUT rats $(1.366 \pm 0.05)$ while MDA significantly reduced $p<0.05$ in $\mathrm{DT}_{7.5}$ $(49.16 \pm 0.51)$ and $\mathrm{DT}_{10}(33.64 \pm 0.42)$ rats when compared to DUT rats $(99.93 \pm 4.79)$. This study revealed that VCO has a hypoglycemic action, enhances insulin secretion and also ameliorates oxidative stress induced in type I (alloxan-induced diabetic) male rats.

Keywords: Virgin Coconut Oil; Oxidative Stress; Blood Glucose; Glucose Tolerance

\section{INTRODUCTION}

Diabetes mellitus characterized by hyperglycaemia, is due to the deficiency of insulin secretion or its action. It has been associated with a syndrome of disturbance in the homeostasis of carbohydrate, fat and protein metabolism [1]. Diabetes mellitus has been categorized into type 1 and type 2 diabetes. Type 1 diabetes refers to deficiency of endogenous insulin which is caused by a cellular-mediated auto immune destruction of the beta cells in the pancreas which produces insulin. And type 2 diabetes is as a result of a decreased response to insulin by its receptors, which is also referred to as insulin resistance $[1,2]$.

Oxidative stress contributes significantly to the pathophysiology of several diseases which include diabetes [3]. Alloxan, a chemical used in inducing diabetes acts mainly by the generation of reactive oxygen species (ROS) [3]. It preferentially accumulates in the GLUT2 glucose transporter in the pancreatic beta cells and subsequently leads to the death of the cells. Therefore alloxan is a model compound when studying diabetes as a 
result of ROS mediated beta cell toxicity.

Historically, coconut oil has been renowned for its medicinal and nutritional value. Studies on the biological effects of coconut oil have proven that it ameliorates oxidative stress by boosting the antioxidant defense system, mopping up free radicals and reducing lipid peroxidation $[4,5]$. It has also been reported to suppress microbial and viral activities [6], promote weight loss and enhance thyroid function [7]. Other researches have also reported that coconut oil possesses anti-inflammatory and anti-ulcerogenic effect [8], while also having the ability to increase the level of high density lipoprotein (HDL) cholesterol and to reduce the level of low density lipoprotein (LDL) in serum and tissues [4].

Copra oil and virgin coconut oil (VCO) are the two main types of coconut oil. Copra oil is extracted from the dried endosperm of the coconut fruit while VCO is produced by a "wet" extraction process from the fresh endosperm of the coconut fruit [9]. The mode of extraction of VCO makes it more beneficial than copra oil. This is because no chemicals are used and there is little or no application of heat during its extraction. Therefore it retains more of the natural active components which include polyphenols which have been proven to boost the antioxidant defense system [4].

The present study therefore, determined the possible role of the antioxidant effect of VCO on oxidation/peroxidation linked with diabetes mellitus in alloxan induced diabetic rats as well as its possible effect on glucose homeostasis.

\section{MATERIALS AND METHODS}

\subsection{Animals}

Male Sprague-Dawley rats weighing 120 - $150 \mathrm{~g}$ were obtained from the Laboratory Animal House of the College of Medicine of the University of Lagos. The rats were allowed to acclimatize for two weeks before the commencement of the experiment and were fed with standard rat chow and water ad libitum at $20^{\circ} \mathrm{C}-25^{\circ} \mathrm{C}$ under a $12 \mathrm{~h} \mathrm{light/dark}$ cycle. All animal handling and experiment protocols complied with the international guidelines for laboratory animals as supported by the College of Medicine of the University of Lagos ethical committee.

\subsection{Experimental Groups}

Rats were randomly divided into 4 groups $(\mathrm{n}=6)$ : Group 1, control (C) received $0.5 \mathrm{ml}$ distilled water; Group 2, diabetic untreated (DUT); Group 3, diabetic treated with $7.5 \mathrm{ml} / \mathrm{kg}$ body weight of $\mathrm{VCO}\left(\mathrm{DT}_{7.5}\right)$ and Group 4, diabetic treated with $10 \mathrm{ml} / \mathrm{kg}$ body weight of $\operatorname{VCO}\left(\mathrm{DT}_{10}\right)$. Seventy two hours following the induction of diabetes, VCO was administered orally for 4 weeks daily at the appropriate dose for Groups 3 and 4 animals.

\subsection{Induction of Diabetes}

Following 2 weeks acclimatization of the rats, Alloxan monohydrate (manufactured by Denixco Private limited, India) was used to induce type 1 diabetes in Groups 2, 3 and 4. A dose of $100 \mathrm{mg} / \mathrm{kg}$ body weight of Alloxan monohydrate was administered only once intraperitoneally. A mild pressure was applied at the spot of injection to enhance absorption. After 3 days of administration the fasting blood glucose level of these rats were measured. Rats with fasting blood glucose level above $200 \mathrm{mg} / \mathrm{dl}$ were considered diabetic.

\subsection{Measurement of Blood Glucose}

Blood glucose level was measured using One Touch Ultra test strips (Lifescan Inc. Milpitas, USA). Blood was obtained from the rats at the tip of rat's tail. The blood was dropped on the test strips already inserted in a One Touch Ultra Easy Glucometer (Lifescan Inc. Milpitas, USA). The glucose levels of the animal were displayed on the glucometer in about 5 seconds. Blood glucose level was measured at the beginning of the experiment and after 4 weeks.

\subsection{Preparation of Virgin Coconut Oil}

Mature coconuts were bought from Mushin Market, Lagos, Nigeria. VCO was extracted using the wet extraction method [4]. The solid endosperm of mature coconut was crushed and made into thick slurry. About $500 \mathrm{ml}$ of water was added to the slurry obtained and squeezed through a fine sieve to obtain coconut milk. The resultant coconut milk was left for about 24 hours to facilitate the gravitational separation of the emulsion. Demulsification produced layers of an aqueous phase (water) on the bottom, an emulsion phase (cream) in the middle layer and an oil phase on top. The oil on top was scooped and warmed for about 3 minutes to remove moisture. The obtained oil was then filtered and stored at room temperature.

\subsection{Oral Glucose Tolerance Test (OGTT)}

On the 4th week of the experiment, all groups were subjected to oral glucose tolerance test (OGTT). The rats were fasted overnight for sixteen-hour (16-h) and subsequently challenged with a glucose load of $2 \mathrm{ug} / \mathrm{kg}$ body weight. Blood glucose levels were determined at $0 \mathrm{~h}$ (pre-glucose treatment) and at 30,60, 90, 120 and 180 min (post glucose treatment). The glucose levels were measured using a complete blood glucose monitoring system (One-Touch Ultra Easy Glucose Meter, Lifescan 
Inc. Milpitas, USA).

\subsection{Sample Collection}

The rats were anesthetized by intramuscular injection of $50 \mathrm{mg} / \mathrm{kg}$ of ketamine. The liver was removed and homogenized in phosphate buffer, $\mathrm{pH} 7.4$ and stored at $-20^{\circ} \mathrm{C}$. Blood samples were also collected from the ventricle of the heart, allowed to clot and spun at $3000 \mathrm{rmp}$ to obtain serum sample for insulin assay.

\subsection{MDA Level}

As a marker of lipid peroxidation, the level of malondialdehyde (MDA) in the liver homogenate was measured [10]. $1 \mathrm{ml}$ of the tissue homogenate was thoroughly mixed with $2 \mathrm{ml}$ of TCA-TBA-HCl solution and heated for 15 minutes in a water bath. After cooling, the precipitate is removed by centrifugation and the absorbance measured at $535 \mathrm{~nm}$ is taken as an index of lipid peroxidation.

\subsection{SOD, CAT and GSH Activities}

At the end of the 4 week period of the experiment, the activity of the superoxide dismutase (SOD) enzyme in the liver homogenate was determined [11]. The reaction was carried out in $0.5 \mathrm{~m}$ sodium carbonate buffer $\mathrm{pH} 10.2$ and was initiated by the addition of $3 \times 10^{-4}$ epinephrine in $0.005 \mathrm{~N} \mathrm{HCl}$. The absorbance was read at $320 \mathrm{~nm}$. Catalase (CAT) activity was determined by measuring the exponential disappearance of $\mathrm{H}_{2} \mathrm{O}_{2}$ at $240 \mathrm{~nm}$ and expressed in units/mg of protein [12]. Reduced glutathione (GSH) content of the liver homogenate was determined [13], based on the reaction of Ellman's reagent 5,5'dithiobis-2-nitrobenzoic acid (DNTB) with the thiol group of GSH at $\mathrm{pH} 8.0$ to produce 5-thiol-2-nitrobenzoate which is yellow at $412 \mathrm{~nm}$. Absorbance was recorded using UV-Visible Spectrophotometer in all measurement. The protein concentrations of the samples were measured using the method of Bradford [14].

\subsection{Serum Insulin Level}

Enzyme-Linked Immunosorbent Assay (ELISA) was used to measure the level of insulin in the serum sample obtained from the animal. The protocol used was as described by the manufacturer of the assay kit (Enzo-Life Science).

\subsection{Statistical Analysis}

Data were presented as mean and Standard Error of Mean (SEM). One-way ANOVA and Tukey's post hoc test was used to determine the specific pairs of groups that were statistically different at $p<0.05$. Analysis was performed with GraphPad software.

\section{RESULTS}

\subsection{Fasting Blood Glucose}

Fasting blood glucose was measured at 72 hours post alloxan injection. Hyperglycemia was observed in DUT, $\mathrm{DT}_{7.5}$, and $\mathrm{DT}_{10}$ rats. After four weeks of coconut oil treatment, $\mathrm{DT}_{7.5}$ and $\mathrm{DT}_{10}$ rats showed a significant reduction $(\mathrm{p}<0.05)$ in fasting blood glucose level compared with DUT rats (Figures 1 and 2).

\subsection{Oral Glucose Tolerance Test (OGTT)}

After 4 weeks administration of coconut oil, glucose concentration (pre glucose challenge) in both $\mathrm{DT}_{7.5}$ and $\mathrm{DT}_{10}$ rats showed a significantly reduced glucose concentration when compared with DUT rats. As expected, there was an initial increase in blood glucose 30 minutes post glucose challenge which reduced over time as presented in Figure 2. Three hours post glucose challenge showed that $\mathrm{DT}_{7.5}$ and $\mathrm{DT}_{10}$ significantly reduced blood glucose level when compared with DUT rats. The effect

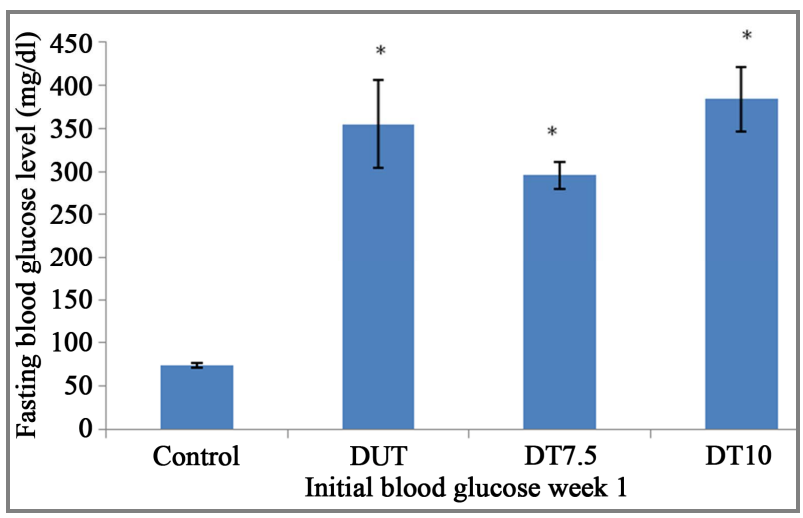

Figure 1. Fasting blood glucose level $(\mathrm{mg} / \mathrm{dl})$ of diabetic rats induced with alloxan. Values are expressed as mean \pm S.E.M. ${ }^{*} \mathrm{p}<0.05$ is significant compared with Group 1 (control).

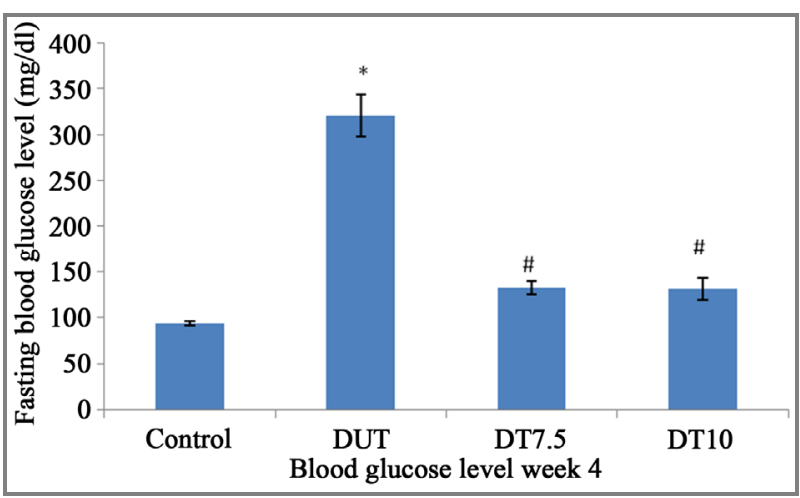

Figure 2. Effect of 4 weeks VCO supplementation on fasting blood glucose level $(\mathrm{mg} / \mathrm{dl})$ in alloxan induced diabetic rats. Values are expressed as mean \pm S.E.M. ${ }^{*} \mathrm{p}<0.05$ is significant compared with Group 1 (control). ${ }^{*} p<0.05$ is significant compared with Group 2 (diabetes untreated). 
of $\mathrm{DT}_{10}$ was more effective than that of $\mathrm{DT}_{7.5}$ (Figure 3).

\subsection{Antioxidant Enzymes Activities and MDA Levels}

MDA level was significantly increased in DUT rats when compared to control ( $\mathrm{p}<0.05)$, however, MDA levels were significantly reduced in $\mathrm{DT}_{7.5}$ and $\mathrm{DT}_{10}$ rats compared with DUT rats. Though a significant reduction in $\mathrm{DT}_{7.5}$ rats was observed when compared with DUT rats, the value observed compared with the control still shows lipid peroxidation (Table 1). In the antioxidant enzymes, SOD activity was significantly reduced in DUT rats when compared with control. $\mathrm{DT}_{7.5}$ and $\mathrm{DT}_{10}$ significantly increased the activity of SOD when compared with DUT rats. The enhancement in SOD activity however was still significantly lower compared with the control values. The activity of GSH was significantly reduced in DUT rats when compared with control. However, $\mathrm{DT}_{10}$ rats significantly increased the activity of GSH while $\mathrm{DT}_{7.5}$ had no effect on the activity of GSH when compared with DUT rats. Lastly, CAT activity was reduced in DUT treated rats when compared with control rats. $\mathrm{DT}_{7.5}$ and $\mathrm{DT}_{10}$ significantly increased the activity of CAT when compared with DUT rats. $\mathrm{DT}_{10}$ enhanced this activity more than the control rats while this activity was still decreased in $\mathrm{DT}_{7.5}$ rats compared to control rats (Table 1).

\subsection{Serum Insulin Level}

Table 2 shows the serum insulin level of male rats treated with VCO. DUT rats shows a significantly reduced insulin level when compared control. $\mathrm{DT}_{10}$ alone significantly increased the level of insulin when compared with DUT rats. Though the values of $\mathrm{DT}_{7.5}$ were increased it was however not significant and the values obtained was still significantly lower than those of the control rats.

\section{DISCUSSION}

Alloxan, used in inducing diabetes is a toxic glucose analogue that generates ROS in the presence of intracellular thiols [3]. The beta cells of the pancreas have a low antioxidative defence capacity, thus the generation of ROS by alloxan leads to the death of these cells. This is possible due to the reduction product of the reaction, dialuric acid, which generates hydrogen peroxide, superoxide radicals and hydroxyl radicals. These radicals are responsible for the death of the beta cells and the ensuing state of insulin-dependent alloxan diabetes [3].

This study reports marked hyperglycemia 72 hours post alloxan injection (100 mg/kg body weight). This is supported by other previous studies and reports [15-17]. Four weeks of treatment with VCO decreased the fasting blood glucose level in $\mathrm{DT}_{7.5}$ and $\mathrm{DT}_{10}$ rats when compared with DUT rats. Supporting the report that coconut oil has a hypoglycemic effect $[18,19]$. Since, alloxan generates ROS to impair the beta cell function; it is possible that VCO alleviates blood glucose level due to its antioxidant property. It is possible that the beta cells response to oxidative stress might have been enhanced thus enabling the cells to carry out their function of insulin production. Consequently, this increase in insulin production will lead to reduced blood glucose.

Oral glucose tolerance test is used to measure insulin function or the degree of peripheral utilization of glucose [20]. In this study, following glucose administration, there was a minimal rise in the blood glucose level which fell below the control value after 2 hours in the control rats. In DUT, $\mathrm{DT}_{7.5}$ and $\mathrm{DT}_{10}$ rats there was a marked rise in blood glucose level after the glucose challenge and the blood glucose level failed to return to the control value

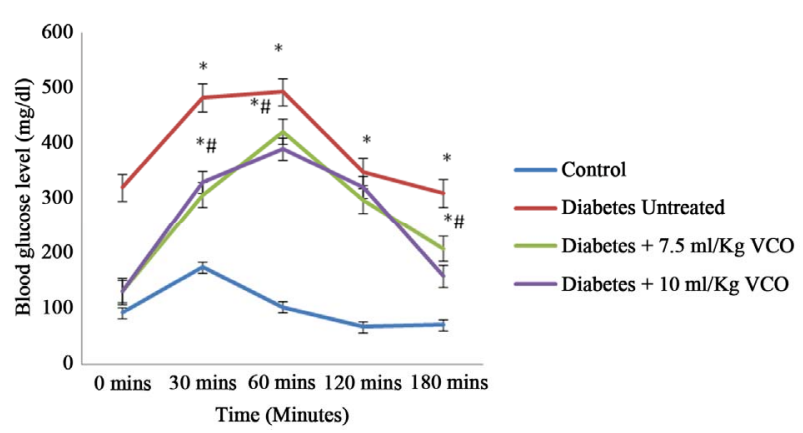

Figure 3. Effect of virgin coconut oil (VCO) on oral glucose tolerance test (OGTT). Values are expressed as mean \pm S.E.M. ${ }^{*} \mathrm{p}<0.05$ is significant compared with Group 1 (control). ${ }^{\#} \mathrm{p}<$ 0.05 is significant compared with Group 2 (diabetes untreated).

Table 1. Effect of VCO on the activity of superoxide dismutase, glutathione, catalase and malondialdehyde levels.

\begin{tabular}{lcccc}
\hline & Control (C) & Diabetes untreated (DUT) & Diabetes $+7.5 \mathrm{ml} / \mathrm{kg} \mathrm{VCO}\left(\mathrm{DT}_{7.5}\right)$ & ${\left.\text { Diabetes }+10 \mathrm{ml} / \mathrm{kg} \mathrm{VCO}_{(\mathrm{DT}}\right)}$. \\
\hline MDA (U/mg protein) & $31.78 \pm 2.18$ & $99.93 \pm 4.79^{*}$ & $49.16 \pm 0.51^{* \sharp}$ & $33.64 \pm 0.42^{\#}$ \\
SOD (U/mg protein) & $3.91 \pm 0.14$ & $1.37 \pm 0.05^{*}$ & $2.63 \pm 0.04^{* \sharp}$ & $2.26 \pm 0.32^{* \sharp}$ \\
GSH (U/mg protein) & $0.11 \pm 0.007$ & $0.03 \pm 0.004^{*}$ & $0.04 \pm 0.008^{*}$ & $0.39 \pm 0.022^{* \sharp}$ \\
CAT (U/mg protein) & $25.87 \pm 0.96$ & $10.98 \pm 0.60^{*}$ & $17.63 \pm 0.61^{* \sharp}$ & $30.88 \pm 0.97^{* \sharp}$ \\
\hline
\end{tabular}

Values are expressed as mean \pm S.E.M. ${ }^{*} \mathrm{p}<0.05$ is significant compared with control. ${ }^{*} \mathrm{p}<0.05$ is significant compared with diabetes untreated group. 
Table 2. Effect of virgin coconut oil (VCO) on serum insulin level.

\begin{tabular}{cc}
\hline & Insulin level $(\boldsymbol{\mu} \mathbf{i u} / \mathbf{m l})$ \\
\hline Control (C) & $3.05 \pm 0.25$ \\
Diabetes untreated (DUT) & $1.19 \pm 0.04^{*}$ \\
Diabetes $+7.5 \mathrm{ml} / \mathrm{kg} \mathrm{VCO}\left(\mathrm{DT}_{7.5}\right)$ & $1.90 \pm 0.40^{*}$ \\
Diabetes $+10 \mathrm{ml} / \mathrm{kg} \mathrm{VCO}\left(\mathrm{DT}_{10}\right)$ & $2.50 \pm 0.03^{\#}$ \\
\hline
\end{tabular}

Values are expressed as mean \pm S.E.M. ${ }^{*} \mathrm{p}<0.05$ is significant compared with Control. ${ }^{\#} \mathrm{p}<0.05$ is significant compared with Diabetes untreated group.

even after 3 hours indicating impairment in glucose tolerance which is an indication of diabetes. $\mathrm{In}^{\mathrm{DT}_{7.5}}$ and $\mathrm{DT}_{10}$ rats there was a significant improvement in glucose tolerance compared with the DUT rats, supporting the view that ingestion of VCO improves glucose tolerance in diabetic rats [21]. In addition, the $10 \mathrm{ml} / \mathrm{kg}$ dosage of VCO proved to have a greater effect as the blood glucose level in $\mathrm{DT}_{10}$ rats after 3 hours of glucose challenge was closer to the control value than in $\mathrm{DT}_{7.5}$ rats.

It has been reported that the lauric oil in VCO possesses insulino-tropic properties [18]. Serum insulin was increased in $\mathrm{DT}_{10}$ rats with a non significant increase in $\mathrm{DT}_{7.5}$ rats compared with DUT rats. Since the dosage of $7.5 \mathrm{ml} / \mathrm{kg}$ body weight of VCO could not elevate serum insulin, it implies that the $10 \mathrm{ml} / \mathrm{kg}$ body weight dose is more effective in the control of glucose homeostasis than the $7.5 \mathrm{ml} / \mathrm{kg}$ body weight. This is evidenced by the reduction in blood glucose level and the improvement in glucose tolerance compared to DUT rats as discussed earlier.

Antioxidant enzymes are critical part of cellular protection against reactive oxygen species and ultimately oxidative stress. Oxidative stress is determined by the balance between the generation of ROS such as superoxide anion $\left(\mathrm{O}_{2}^{-}\right)$and the antioxidant defense systems such as superoxide dismutase (SOD). Antioxidants enzymes involved in the elimination of ROS include SOD, CAT and GSH, respectively. The present study showed a decrease in the activity of all measured antioxidants enzymes in DUT rats. This indicates a decrease in the antioxidant defense system. However treatment with VCO in $\mathrm{DT}_{7.5}$ and $\mathrm{DT}_{10}$ rats increased the activities of the antioxidant enzymes. Since oxidative stress contributes significantly to the pathophysiology of diabetes [22], substances that suppress oxidative stress might be therapeutically beneficial. Studies have shown that exogenously administered antioxidants have protective effects on diabetes, thus providing insight into the relationship between free radicals and diabetes [20,22-24]. The reduction in fasting blood glucose of rats treated with VCO after 4 weeks and a decrease in the OGTT of the rats compared with the diabetic untreated rats can be associated to the antioxidant effect of VCO.

\section{CONCLUSION}

VCO alleviates hyperglycemia and improves glucose tolerance probably by its antioxidant effect which consequently leads to improvement of insulin secretion as examined in this study. The study also shows that a dosage of $10 \mathrm{ml} / \mathrm{kg}$ body weight of VCO is quite beneficial and more effective than that of $7.5 \mathrm{ml} / \mathrm{kg}$ body weight. This was evident because the $7.5 \mathrm{ml} / \mathrm{kg}$ body weight did not increase insulin secretion and possibly because of the higher OGTT values.

\section{REFERENCES}

[1] American Diabetes Association (2010) Diagnosis and classification of diabetes mellitus. Diabetic Care, 33.

[2] World Health Organization (2011) Diabetes fact sheet. Sheet number 312 August.

[3] Lenzen, S. (2008) The mechanisms of alloxan- and streptozotocin-induced Diabetes. Diabetologia, 51, 216-226. http://dx.doi.org/10.1007/s00125-007-0886-7

[4] Nevin, K.G. and Rajamohan, T. (2006) Virgin coconut oil supplemented diet increases the antioxidant status in rats. Food Chemistry, 99, 260-266.

http://dx.doi.org/10.1016/j.foodchem.2005.06.056

[5] Dosumu, O.O., Duru, F.I.O., Osinubi, A.A., Oremosu, A.A. and Noronha, C.C. (2010) Influence of virgin coconut oil (VCNO) on oxidative stress, serum testosterone and gonadotropic hormones (FSH, LH) in chronic ethanol ingestion. Agriculture and Biology Journal of North America, 1, 1126-1132.

[6] Van Immerseel, F., De Buck, J. and Boyen, F. (2004) Medium-chain fatty acids decrease colonization and invasion through hilA suppression shortly after infection of chickens with Salmonella enterica serovar enteritidis. Applied and Environmental Microbiology, 70, 3582-3587. http://dx.doi.org/10.1128/AEM.70.6.3582-3587.2004

[7] Takeuchi, H., Sekine, S., Kojima, K. and Aoyama, T. (2008) The application of medium-chain fatty acids: Edible oil with a suppressing effect on body fat accumulation. Asia Pacific Journal of Clinical Nutrition, 17, 320-324.

[8] Anosike, C.A. and Obidoa, O. (2010) Anti-inflammatory and anti-ulcerogenic effect of ethanol extract of coconut (Cocos nucifera) on experimental rats. African Journal of Food, Agriculture, Nutrition and Development, 10, 10-16.

[9] Cretney, J. and Tafunai, A. (2004) Tradition, trade, and technology: Virgin coconut oil in samoa. In Chains of Fortune: Linking Women Producers and Workers with Global Markets, 45-74.

[10] Uchiyama, M. and Mihara, M. (1978) Determination of malonaldehyde precursor in tissues by thiobarbituris acid test. Analytical Biochemistry, 86, 271-278. http://dx.doi.org/10.1016/0003-2697(78)90342-1

[11] Sun, M. and Zigmam S. (1978) An improved spectro- 
photomeric assay for superoxide dismutase based on epinephrine autooxidation. Analytical Biochemistry, 90, 8189. http://dx.doi.org/10.1016/0003-2697(78)90010-6

[12] Aebi, H. (1984) Catalase in vitro. Methods in Enzymology, 8, 121-126. http://dx.doi.org/10.1016/S0076-6879(84)05016-3

[13] Van Dooran, R., Liejdekker, C.M. and Handerson, P.T. (1978) Synergistic effects of phorone on the hepatotoxicity of bromobenzene and paracetamol in mice. Toxicology, 11, 225-233. http://dx.doi.org/10.1016/S0300-483X(78)91389-6

[14] Bradford, M.M. (1976) A rapid and sensitive method for the quantification of microgram quantities of protein utilizing the principle of protein-dye binding. Analytical Biochemistry, 72, 248-254. http://dx.doi.org/10.1016/0003-2697(76)90527-3

[15] Szkudelski, T. (2001) The mechanism of alloxan and streptozotocin action in B cells of the rat pancreas. Physiological Research, 50, 536-546.

[16] Lenzen, S., Tiedge, M., Jorns, A. and Munday, R. (1996) Alloxan derivatives as a tool for the elucidation of the mechanism of the diabetogenic action of alloxan. In: Shafrir, E., Ed., Lessons from Animal Diabetes. Birkhäuser, Boston, 113-122. http://dx.doi.org/10.1007/978-1-4612-4112-6 8

[17] Jorns, A., Munday, R., Tiedge, M. and Lenzen, S. (1997) Comparative toxicity of alloxan, $\mathrm{N}$-alkylalloxans and ninhydrin to isolated pancreatic islets in vitro. Journal of Endocrinology, 155, 283-293. http://dx.doi.org/10.1677/joe.0.1550283

[18] Garfinkel, M., Lee, S., Opara, E.C. and Akwari, O.E. (1992) Insulinotropic potency of lauric acid. A metabolic rationale for medium chain fatty acids (MCF) in TPN formulation. Journal of Surgical Research, 52, 328-333. http://dx.doi.org/10.1016/0022-4804(92)90111-C

[19] Sadikot, S.M. (2005) Coconut for health nutrition. Jakarta, APCC, 6.

[20] Kim, S.S., Gallaher, D.D. and Csallany, A.S. (2000) Vitamin $\mathrm{E}$ and probucol reduce urinary lipophilic aldehydes and renal enlargement in streptozotocin induced diabetic rats. Lipids, 35, 1225-1237. http://dx.doi.org/10.1007/s11745-000-0639-2

[21] Siddalingaswamy, M., Rayaorth, A. and Khanum, F. (2011) Anti-diabetic effects of cold and hot extracted virgin coconut oil. Journal of Diabetes Mellitus, 1, 118-123. http://dx.doi.org/10.4236/jdm.2011.14016

[22] Maritim, A.C., Sanders, R.A. and Watkins, J.B. (2003) Diabetes, oxidative stress and antioxidants: A review. Journal of Biochemical and Molecular Toxicology, 17, 24-38. http://dx.doi.org/10.1002/jbt.10058

[23] Mekinova, D., Chorvathova, V., Volkovova, K., Staruchova, M., Grancicova, F., Klvanova, J., Nevin, K.G. and Rajamohan, T. (2004) Beneficial effects of virgin coconut oil on lipid parameters and in vitro LDL oxidation. Clinical Biochemistry, 37, 830-835. http://dx.doi.org/10.1016/j.clinbiochem.2004.04.010

[24] Borenshtein, D.R., Ofri, M., Werman, A., Stark, H.J., Tritschler, W. and Moeller Madar Z. (2001) Cataract development in diabetic sand rats treated with alpha-lipoic acid and its gamma-linolenic acid conjugate. Diabetes/ Metabolism Research and Reviews, 17, 44-50. http://dx.doi.org/10.1002/1520-7560(0000)9999:9999<:: AID-DMRR153>3.0.CO;2-S 